\title{
Effect of annealing on wear resistance and electroconductivity of copper processed by high-pressure torsion
}

\author{
Alexander P. Zhilyaev $\cdot$ I. Shakhova $\cdot$ \\ A. Belyakov $\cdot$ R. Kaibyshev $\cdot$ Terence G. Langdon
}

Received: 11 November 2013/ Accepted: 25 November 2013/Published online: 6 December 2013

(C) Springer Science+Business Media New York 2013

\begin{abstract}
The influences of annealing temperature on the wear properties and electrical conductivity of $\mathrm{Cu}$ were studied after processing by high-pressure torsion (HPT). The annealing of $\mathrm{Cu}$ specimens processed by HPT leads to an increase in electroconductivity and a decrease in the wear rate. It is apparent that a nanotribolayer at the surface induced during wear sliding plays a more significant role than the ultrafine-grained structure. A slight increase was observed in the microhardness of HPT copper specimens upon annealing at a relatively low temperature $\left(100^{\circ} \mathrm{C}\right)$, and this is most likely due to a change in texture. The annealing leads to an increase in the Taylor factor by $\sim 5 \%$, which is in good agreement with the increase in the microhardness level which is also by $\sim 5 \%$. It is apparent that low-temperature annealing of HPT copper may produce optimal properties of the specimens including high strength and electroconductivity with a lower wear rate.
\end{abstract}

A. P. Zhilyaev · T. G. Langdon

Materials Research Group, Faculty of Engineering and the Environment, University of Southampton,

Southampton SO17 1BJ, UK

A. P. Zhilyaev ( $\square)$

Institute for Metals Superplasticity Problems, Khalturina 39, Ufa 450001, Russia

e-mail: a.zhilyaev@ soton.ac.uk

I. Shakhova $\cdot$ A. Belyakov $\cdot$ R. Kaibyshev

Belgorod State University, Pobeda 85, Belgorod 308015, Russia

T. G. Langdon

Departments of Aerospace \& Mechanical Engineering and

Materials Science, University of Southern California,

Los Angeles, CA 90089-1453, USA

\section{Introduction}

After the successful processing of ultrafine-grained (UFG) and nanostructured (NS) metallic materials using severe plastic deformation (SPD) [1], there have been many attempts to reveal the advantages of these novel microstructures not only in terms of structural applications but also for functional properties [2]. The latter includes biomedical applications [3], the development of corrosionresistant materials, high fatigue life materials, enhanced magnetic and thermoelectric properties, and improved hydrogen adsorption kinetics [2]. Recently, a great attention was paid on achieving high strength and high electroconductivity in Cu-based alloys [4-6], and it was claimed that such materials possess both characteristics simultaneously. However, it is evident that a reduction in grain size will lead to decreasing electroconductivity due to enhanced scattering of the free electrons at lattice defects. At the same time, an increased strength appears to lead to an enhancement in wear resistance according to Archard's law. Nevertheless, a recent review indicated that deviations from Archard's law may take place owing to the large plane strains at the contact points and the adhesive transfer and mechanical mixing [7]. Several reports on the tribological behavior of copper [8-10] demonstrate the complex nature of wear; specifically, the wear rate may be a function of numerous parameters. Moreover, it was demonstrated very recently that significant grain refinement, and consequently, strengthening, may not lead to improved wear properties in commercial pure copper but rather to an increase in the steady-state wear rate with a consequent decrease in the electroconductivity [11].

There are now many reports of grain refinement in pure copper processed by equal-channel angular pressing (ECAP) [12-18], high-pressure torsion (HPT) [11, 19-21], 
and machining or plain strain machining (PSM) [22] as well as using surface mechanical attrition treatment (SMAT) [23]. The tribological properties have been studied in HPT copper [24], PSM copper chips [25], SMAT copper specimens [26], and in copper processed by dynamic plastic deformation (DPD) [27]. The smallest grain size ( $\sim 200 \mathrm{~nm})$ in copper was obtained by HPT [28] and by HPT combined with other SPD techniques such as ECAP, PSM, and cold rolling [29].

In practice, the simplest way to achieve UFG copper is by HPT which permits the processing of disks suitable for experiments on wear resistance and also measurements of electroconductivity. In an earlier report [11], it was demonstrated that significant grain refinement is not necessarily correlated with improved wear resistance. Accordingly, the present research was initiated to monitor the wear resistance and the electroconductivity as a function of annealing temperature for pure copper processed by HPT.

\section{Experimental materials and procedure}

Disks of copper were used as the starting material. The material was purchased from GoodFellow ${ }^{\mathrm{TM}}$, and the typical chemical composition was given as (in ppm) $\mathrm{Ag}$ 500, $\mathrm{Bi}<10, \mathrm{~Pb}<50, \mathrm{O} 400$, and other metals $<300$. The HPT specimens were in the form of disks having diameters of $10 \mathrm{~mm}$ and thicknesses of about $1 \mathrm{~mm}$. These disks were processed at room temperature by HPT for a total of $N=5$ turns under an applied pressure of $P=6.0 \mathrm{GPa}$. The processing was conducted under quasi-constrained conditions, where there is a small outflow of material around the periphery of each disk during processing [30, 31]. Parts of the processed specimens were annealed at 100,200 , or $300{ }^{\circ} \mathrm{C}$ for a period of $1 \mathrm{~h}$ with subsequent water quenching. The annealing was conducted using a Nabertherm furnace with automatic temperature control up to $\pm 2^{\circ}$. The softening during subsequent annealing after HPT was monitored using Vickers microhardness tests with a load of $50 \mathrm{~g}$, and a holding time of $10 \mathrm{~s}$. The specimens for microhardness measurements were mechanically polished on 1000 grit $\mathrm{SiC}$ paper followed by a final polish using a diamond suspension containing monocrystalline diamond with a size of $3 \mu \mathrm{m}$.

Microstructural investigations were performed on sections perpendicular to the axes of HPT using a Quanta 600 FEG scanning electron microscope equipped with an electron backscatter diffraction (EBSD) analyzer incorporating an orientation imaging microscopy (OIM) system. The specimens for EBSD analyses were cut from disks at the halfradius position and then mechanically polished to a mirrorlike state with subsequent electrochemical polishing at room temperature using an electrolyte of $\mathrm{HNO}_{3}: \mathrm{CH}_{3} \mathrm{OH}=1: 3$ with a voltage of $10 \mathrm{~V}$. For all specimens, the EBSD analysis used a step size of $100 \mathrm{~nm}$, and the EBSD maps were subjected to a clean-up procedure involving a grain tolerance angle of $5^{\circ}$ and a minimum grain size of three pixels. The grain sizes were measured using the linear intercept method in transverse and radial directions as the distances between high-angle boundaries with misorientations above $15^{\circ}$. The misorientation distributions were obtained using OIM software EDAX TSL, version 5.2.

The electrical conductivities of all specimens were measured using a four-point probe method [11]. The specimens for the conductivity measurements were prepared following the same procedure as for the microhardness tests.

The wear resistance of three specimens per test was investigated by ball-on-disk type high-temperature tribometer (CSM Instruments). The counterbody of the hightemperature tribometer was Cr6 steel balls having a diameter of $6 \mathrm{~mm}$ with a hardness above $500 \mathrm{Hv}$. The surfaces of the specimens before testing were subjected to a two-step polishing with an initial mechanical polishing on 1000-grit SiC paper followed by a final polishing on a diamond suspension containing monocrystalline diamond with a size of $3 \mu \mathrm{m}$. The wear tests were carried out at room temperature with normal loads of $1.5 \mathrm{~N}$, a sliding speed of $0.04 \mathrm{~m} \mathrm{~s}^{-1}$, a fixed sliding distance of $100 \mathrm{~m}$, and the total time of the wear tests was less than 45 min per sample. After the wear testing, the friction paths were studied using a precision contact profilometer SURTRONIC to determinate the profile of the friction path at selected points on the samples, and a Quanta 200 3D scanning electron microscope (SEM) was used to establish the character of wear. Further details on these procedures can be found in an earlier report [11].

\section{Experimental results}

Microhardness and microstructure of the copper samples

The microhardness and some structural parameters are listed in Table 1 where $d$ is the grain size, and $\rho$ is the dislocation density. It is readily apparent that the annealing temperature has a significant effect on the microhardness. Specifically, an increase in the annealing temperature leads to a decrease of microhardness from 1.45 GPa after HPT to $0.96 \mathrm{GPa}$ after HPT with subsequent annealing at $300{ }^{\circ} \mathrm{C}$. Typical microstructures of $\mathrm{Cu}$ are shown in the left column in Fig. 1, and the right column represents the grain boundary misorientation distributions for all samples. The $\mathrm{Cu}$ samples after HPT show typical deformation microstructures with nearly uniform grains and a high fraction of 
Table 1 Microstructural parameters of HPT copper annealed for $1 \mathrm{~h}$ at different temperatures

\begin{tabular}{|c|c|c|c|c|c|c|c|c|c|}
\hline \multirow[t]{2}{*}{ Specimen } & \multirow[t]{2}{*}{$\mathrm{Hv}(\mathrm{GPa})$} & \multirow[t]{2}{*}{$d(\mu \mathrm{m})$} & \multirow[t]{2}{*}{ PFs max intensity } & \multicolumn{3}{|c|}{ GBs Fraction (\%) } & \multirow[t]{2}{*}{ Taylor factor } & \multirow[t]{2}{*}{ KAM $\left(^{\circ}\right)$} & \multirow[t]{2}{*}{$\rho\left(\mathrm{m}^{-2} \times 10^{15}\right)$} \\
\hline & & & & LAB & $\Sigma 3$ & HAB & & & \\
\hline HPT & 1.45 & 0.37 & 3.22 & 12.8 & 4.9 & 82.3 & 3.005 & 0.822 & 0.86 \\
\hline $\mathrm{HPT}+100{ }^{\circ} \mathrm{C}$ & 1.50 & 0.64 & 3.18 & 12.7 & 31.9 & 55.4 & 3.107 & 0.678 & 0.71 \\
\hline $\mathrm{HPT}+200{ }^{\circ} \mathrm{C}$ & 1.15 & 0.83 & 3.45 & 9.0 & 33.6 & 57.4 & 3.113 & 0.489 & 0.51 \\
\hline $\mathrm{HPT}+300^{\circ} \mathrm{C}$ & 0.96 & 0.91 & 4.84 & 10.5 & 31.5 & 58.0 & 2.967 & 0.617 & 0.65 \\
\hline
\end{tabular}

high-angle boundaries. The average grain size and fraction of high-angle boundaries were measured as $0.37 \mu \mathrm{m}$ and $>75 \%$, respectively. After annealing, the microstructure gradually changes with the increasing temperature, and the substructure within the grains disappears. The average grain sizes increased to $0.64,0.83$, and $0.91 \mu \mathrm{m}$ after annealing at 100,200 , and $300{ }^{\circ} \mathrm{C}$, respectively. In general, the microstructures look similar for all samples. The misorientation distribution after annealing at $100{ }^{\circ} \mathrm{C}$ revealed a large peak at $60^{\circ}$ corresponding to the twin boundaries. The value of this peak increased gradually from $4.9 \%$ for the HPT samples to almost stable values of $31.9,33.6$, and $31.5 \%$ for the HPT samples annealed at 100,200 , and $300{ }^{\circ} \mathrm{C}$, respectively. It is evident from Figs. $2 \mathrm{c}, \mathrm{d}$ that there is a large number of annealing twins within the grains.

There are also some interesting features that were not reported previously. Thus, from Table 1, it appears that there is a slight increase in microhardness level in the specimen annealed at $100{ }^{\circ} \mathrm{C}$. The microhardness value of $1.50 \mathrm{GPa}(150 \mathrm{Hv})$ is higher than for the HPT specimen $(1.45 \mathrm{GPa}$ or $145 \mathrm{Hv})$. The difference in microhardness is within the range of the errors for the $\mathrm{Hv}$ measurements ( $\pm 10 \%$ ), but nevertheless repeating the $\mathrm{Hv}$ measurements showed a consistent increase of microhardness after annealing at $100{ }^{\circ} \mathrm{C}$.

Figure 2 shows (111) pole figures (PF) for the specimens processed by HPT and consequently annealed at different temperatures. In Fig. 2a, it is clearly seen that there is a typical shear texture with a maximum intensity of 3.22 (Table 1). For specimens annealed at 100 and $200{ }^{\circ} \mathrm{C}$, shear texture components indicated by dash lines in Fig. 2 are present. However, new maxima corresponding to an annealing texture have also appeared. The maximum of the texture intensity slightly decreases for the sample annealed at $100{ }^{\circ} \mathrm{C}$ to a value of 3.18 , and this correlates with the apparent increase of microhardness. An increase in the annealing temperature leads to a disappearance of the shear components (Fig. 2d) and an increase of the annealing texture maximum to 4.84 .

The Taylor factors calculated for different specimens (Table 1) increased slightly with the increasing annealing temperature. The Kernel average misorientation (KAM) decreased with the increasing annealing temperature, and accordingly the dislocation density also decreased. It should be noted that the dislocation density was estimated from the relationship $\rho=\frac{8}{3 \sqrt{3}} \frac{\theta_{\mathrm{KAM}}}{b \cdot h}[11]$, and for the HPT sample $\left(0.86 \times 10^{15} \mathrm{~m}^{-2}\right)$, the value was slightly lower than the dislocation density obtained earlier for a sample subjected to machining and HPT $\left(1.31 \times 10^{15} \mathrm{~m}^{-2}\right)$ [11]. However, the present value is in reasonable agreement with a value calculated by van den Beukel's equation [32] and extrapolated to higher strains [33].

\section{Electroconductivity and wear resistance of $\mathrm{Cu}$ samples}

All data on electroconductivity measurements are summarized in the last two columns of Table 2. As expected, the highest conductivity occurred in annealed samples of copper, and the value of the conductivity $\left[5.74 \times 10^{7}\right.$ $(\mathrm{Om} \mathrm{m})^{-1}$ ] is very close to the value of the International Annealed Copper Standard (IACS) established for the conductivity of commercially pure annealed copper of $5.80 \times 10^{7}(\mathrm{Om} \mathrm{m})^{-1}$. It is apparent that the annealing time was not sufficient for full recrystallization. The electroconductivity of HPT copper $\left[3.98 \times 10^{7}(\mathrm{Om} \mathrm{m})^{-1}\right]$ is slightly higher than the one obtained for a sample processed by a combination of HPT and machining $\left[3.67 \times 10^{7}(\mathrm{Om} \mathrm{m})^{-1}\right]$. This is a good indication of consistency in measuring electroconductivity in the copper specimens.

Figure 3 shows the relationship between the friction force and the sliding distance where, for ease of reference, only about each of 250 points are plotted. In general, the friction force reaches a saturated value around of $1.2 \mathrm{~N}$. However, it is apparent that the sliding distances for achieving the saturated level of the friction force are different for the various samples. For example, the specimens annealed at 100 and $300{ }^{\circ} \mathrm{C}$ show a steady-state behavior after a sliding distance of $50 \mathrm{~m}$, whereas for the HPT samples and the samples annealed at $200{ }^{\circ} \mathrm{C}$, the steadystate was attained at $30 \mathrm{~m}$. It is apparent that the slope of the curves changes for all samples at the early stages of the wear tests. After HPT processing, the sample exhibits an 


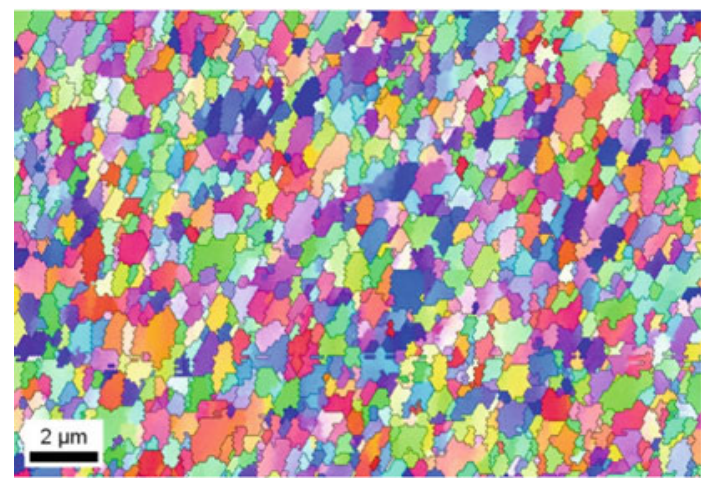

(a)
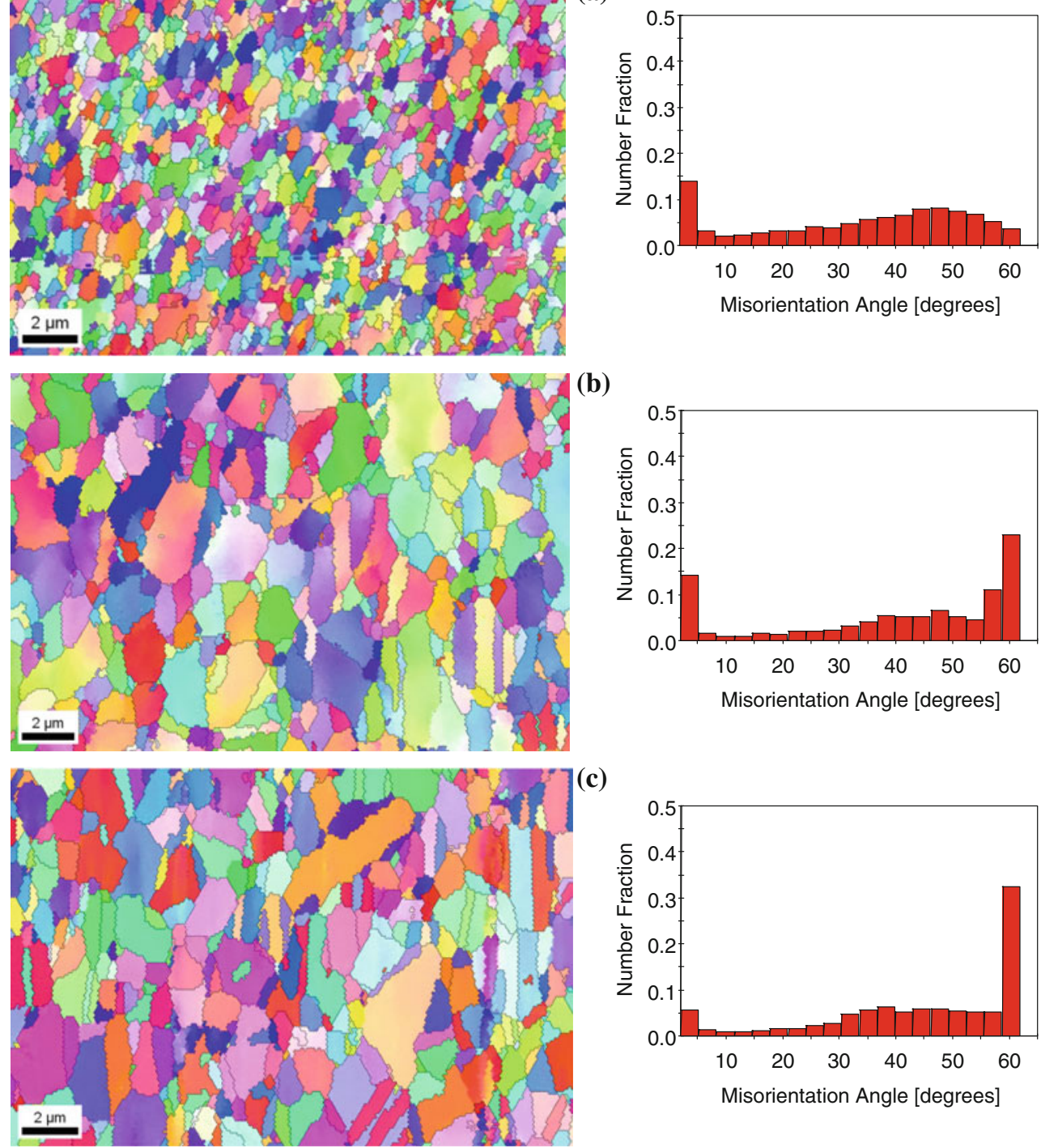

(b)
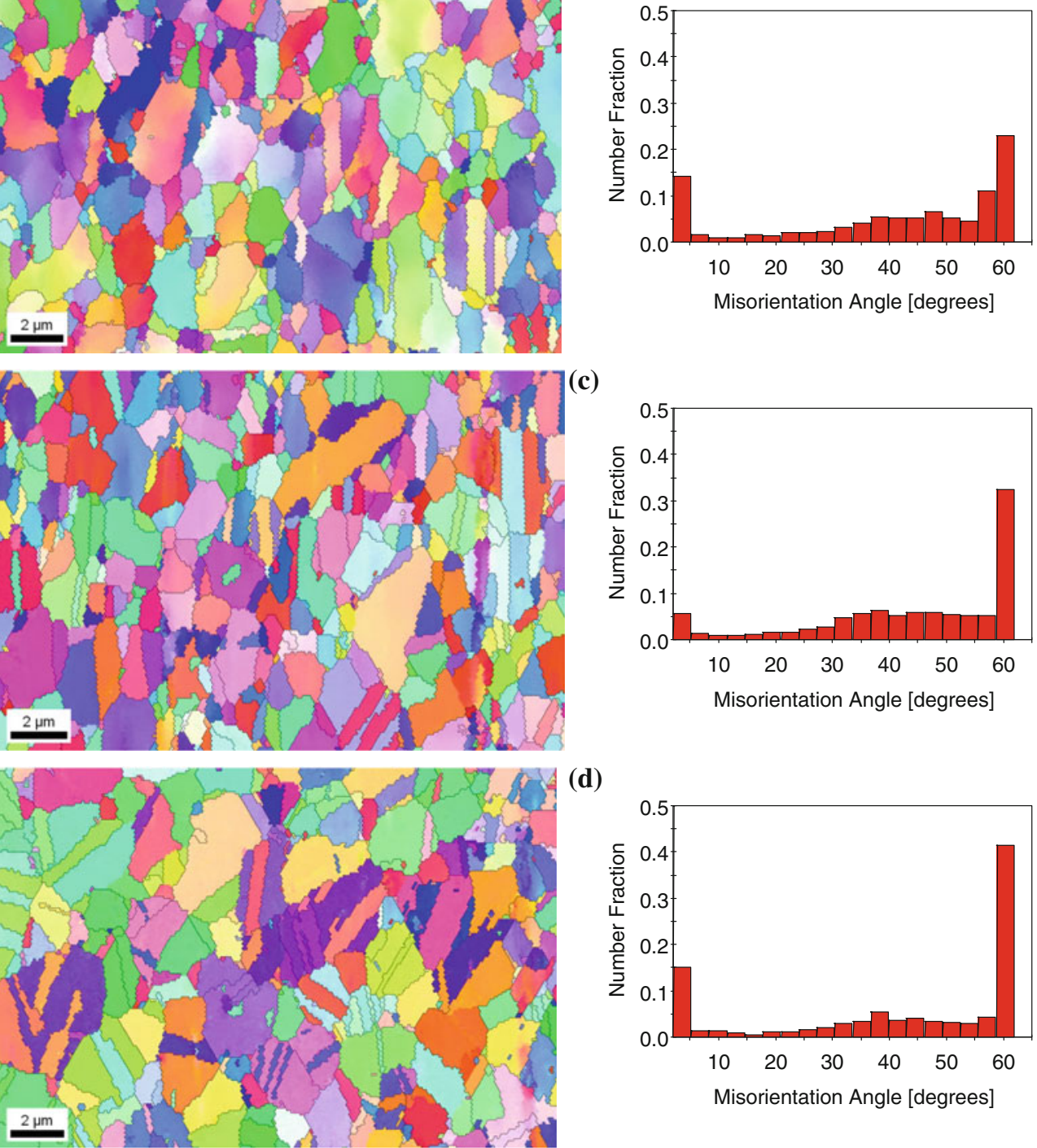

(d)
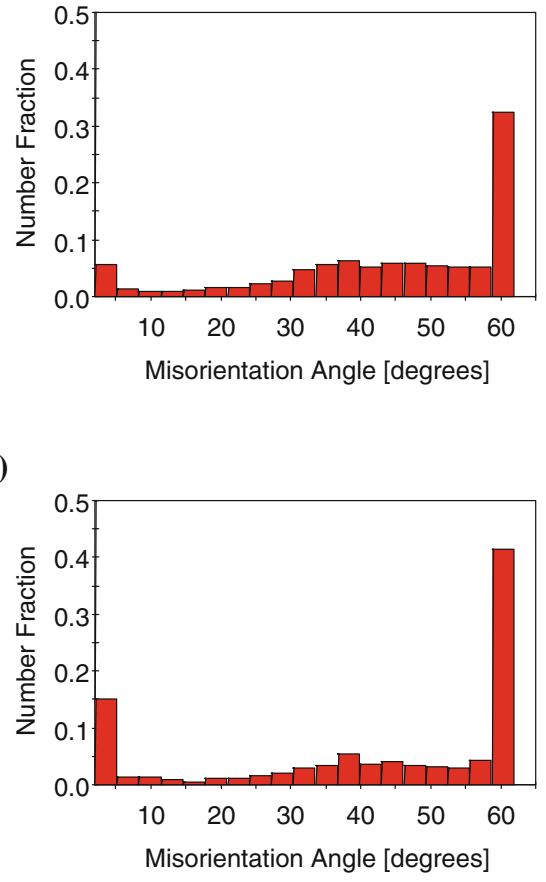

Fig. 1 Typical microstructure developed in $\mathrm{Cu}$ after HPT (a), after HPT with subsequent annealing at $100{ }^{\circ} \mathrm{C}$ during $1 \mathrm{~h}$ (b), after HPT with subsequent annealing at $200{ }^{\circ} \mathrm{C}$ during $1 \mathrm{~h}(\mathbf{c})$, after HPT with

abrupt slope in comparison with the moderate slope of samples after annealing. The wear rate and the friction coefficient (the initial and steady-state values) obtained subsequent annealing at $300{ }^{\circ} \mathrm{C}$ during $1 \mathrm{~h}(\mathbf{d})$, and corresponding misorientation distribution

during the wear tests are summarized in Table 2 for all specimens. The highest wear rate of $10.3 \times 10^{-5} \mathrm{~mm}^{3}$ $(\mathrm{N} \mathrm{m})^{-1}$ was recorded for samples after HPT. Annealing 


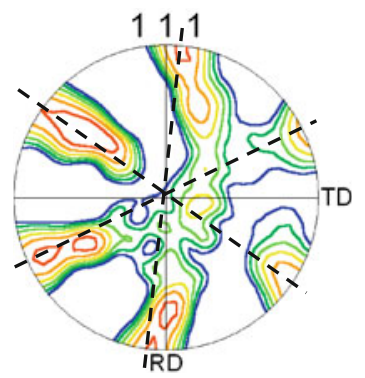

(a)

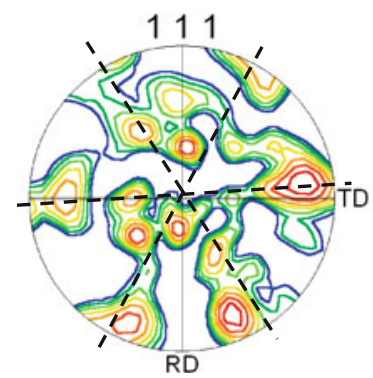

(b)

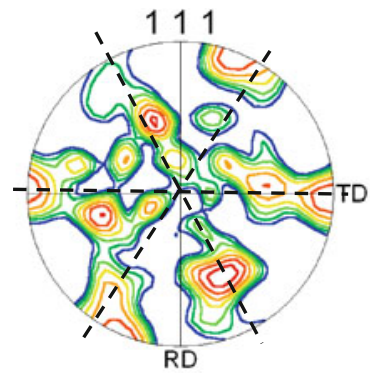

(c)

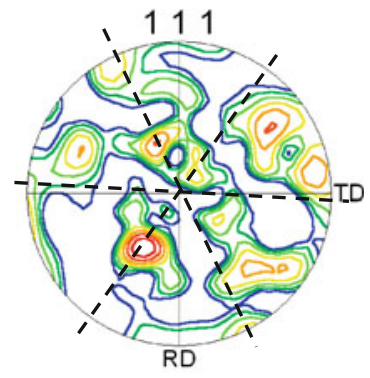

(d)

Fig. 2 Typical (111) PF developed in Cu after HPT (a), after HPT with subsequent annealing at $100{ }^{\circ} \mathrm{C}$ during $1 \mathrm{~h}(\mathbf{b})$, after HPT with

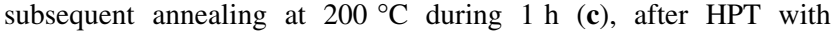

subsequent annealing at $300{ }^{\circ} \mathrm{C}$ during $1 \mathrm{~h}$ (d), and corresponding misorientation distribution

Table 2 Wear parameters and electroconductivity of HPT copper annealed for $1 \mathrm{~h}$ at different temperatures

\begin{tabular}{|c|c|c|c|c|c|}
\hline \multirow[t]{2}{*}{ Specimen } & \multirow[t]{2}{*}{ Wear rate $\left(\mathrm{mm}^{3}(\mathrm{~N} \mathrm{~m})^{-1} \times 10^{-5}\right)$} & \multicolumn{2}{|c|}{ Friction coefficient } & \multicolumn{2}{|c|}{ Electrical conductivity } \\
\hline & & Initial & Steady-state & $(\Omega \mathrm{m})^{-1}, \times 10^{7}$ & $\%$ IACS $^{\mathrm{a}}$ \\
\hline HPT & 10.3 & 0.47 & 0.92 & 3.98 & 65.6 \\
\hline $\mathrm{HPT}+100{ }^{\circ} \mathrm{C}$ & 9.2 & 0.31 & 0.86 & 4.18 & 72.1 \\
\hline $\mathrm{HPT}+200{ }^{\circ} \mathrm{C}$ & 7.6 & 0.47 & 0.88 & 5.02 & 86.6 \\
\hline $\mathrm{HPT}+300{ }^{\circ} \mathrm{C}$ & 5.1 & 0.18 & 0.88 & 5.74 & 99.0 \\
\hline
\end{tabular}

a The International Annealed Copper Standard (IACS) establishes a standard for the conductivity of commercially pure annealed copper of $5.80 \times 10^{7}(\mathrm{Om} \mathrm{m})^{-1}$

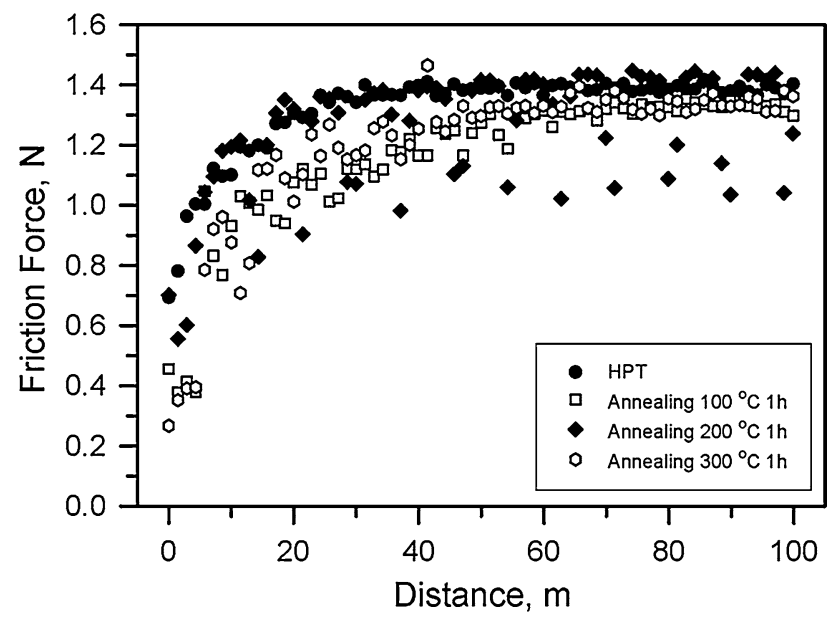

Fig. 3 Relationship between frictional force and distance of sliding for $\mathrm{Cu}$ samples

at $100{ }^{\circ} \mathrm{C}$ led to a reduction in the wear rate to $9.2 \times$ $10^{-5} \mathrm{~mm}^{3}(\mathrm{~N} \mathrm{~m})^{-1}$. With subsequent increases of annealing temperature to $300{ }^{\circ} \mathrm{C}$, the wear rate gradually decreased by twofold to $5.1 \times 10^{-5} \mathrm{~mm}^{3}(\mathrm{~N} \mathrm{~m})^{-1}$ against the severely deformed state. The samples after HPT also demonstrated the highest initial and steady-state friction coefficients of 0.47 and 0.92 , respectively. The steady-state friction coefficient showed a tendency to increase compared with the initial friction coefficient for all types of specimens (Table 2). The value of the steady-state friction coefficient increased almost five times relative to the initial friction coefficient after annealing at $300{ }^{\circ} \mathrm{C}$.

Typical SEM images of the friction tracks after the wear test are shown in Fig. 4 where the white arrows indicate the direction of ball sliding. An overview of all SEM images demonstrates that the type of friction track is very similar after annealing (Fig. 4b-d), whereas the severely deformed sample has another type of friction track (Fig. 4a). It appears that the annealing temperature has no significant effect on the type of friction track. The enlarged SEM images for all the specimens are shown in Fig. 5. In general, the samples after annealing exhibit plastically deformed material within the friction tracks (Fig. 5-d), and it is clearly seen in Fig. $5 b$ that copper is smearing on the surface during the wear test.

\section{Discussion}

Correlations of microhardness and microstructure of HPT copper samples after annealing

One of the unusual characteristics of HPT copper is the small increase in microhardness in the HPT copper annealed at $100{ }^{\circ} \mathrm{C}$ (Table 1). At the same time, the EBSD analysis showed an increasing grain size from $0.37 \mu \mathrm{m}$ 

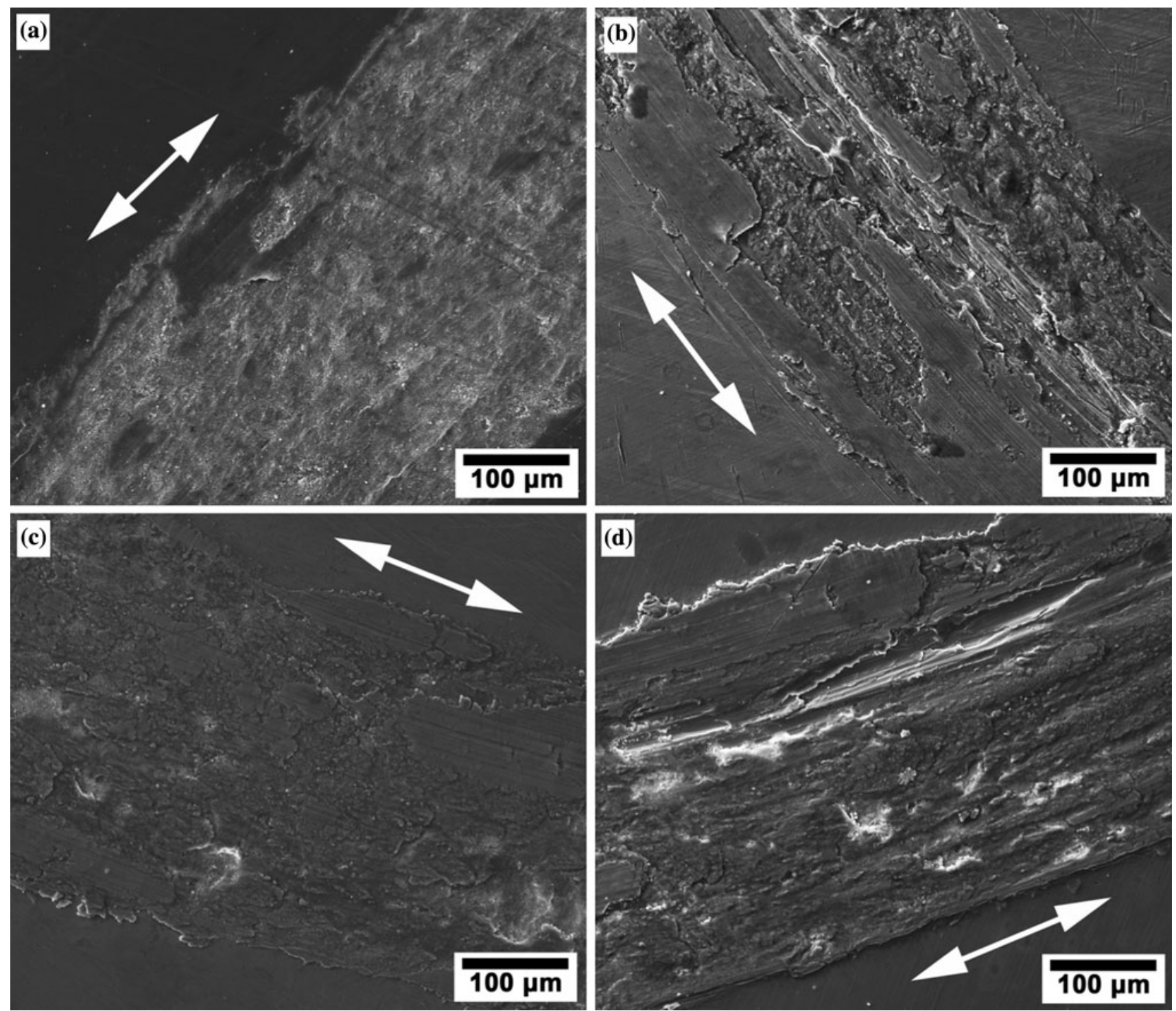

Fig. 4 Typical SEM images of friction path of $\mathrm{Cu}$ samples after HPT (a), after HPT with subsequent annealing at $100{ }^{\circ} \mathrm{C}$ during $1 \mathrm{~h}(\mathbf{b})$, after HPT with subsequent annealing at $200{ }^{\circ} \mathrm{C}$ during $1 \mathrm{~h}(\mathbf{c})$, and

(HPT sample) to $0.64 \mu \mathrm{m}$ (HPT+annealing) which, in principle at least, should result in a softening of the material. Recently, it was claimed that there is also "hardening by annealing" [34] where a similar effect was reported in commercial purity aluminum. Some hypotheses have been proposed to explain this phenomenon. These hypotheses range from a mechanistic explanation based on the residual stresses created by dislocations [35] or the absorption of vacancies by grain boundaries [36] to a sophisticated model including different mechanisms of strengthening at different stages of deformation [37].

In practice, all of these explanations must incorporate the changing of some structural parameters (grain size, dislocation density, etc.) in a manner to favor strengthening

after HPT with subsequent annealing at $300{ }^{\circ} \mathrm{C}$ during $1 \mathrm{~h}(\mathbf{d})$. The white arrows show direction of ball sliding during wear test

upon annealing. However, in the present study there was a concomitant increase in the mean grain size and a decrease in the dislocation density, and it appears that there are no structural features that can be directly attributed to the increase in microhardness. Nevertheless, an analysis of texture and the Taylor factor shows that the texture strengthening may be responsible for the slight increase in $\mathrm{Hv}$. Indeed, in the specimens annealed at $100{ }^{\circ} \mathrm{C}$, a small decrease in the maximum intensity of the PFs was detected from 3.22 for HPT copper to 3.18 for HPT $\mathrm{Cu}$ after annealing at $100{ }^{\circ} \mathrm{C}$. This leads to an increase in the average Taylor factor from 3.005 (HPT copper) to 3.107 (HPT+annealing at $100{ }^{\circ} \mathrm{C}$ ), which is about $3.4 \%$ higher. This calculation is in good agreement with the experimental 

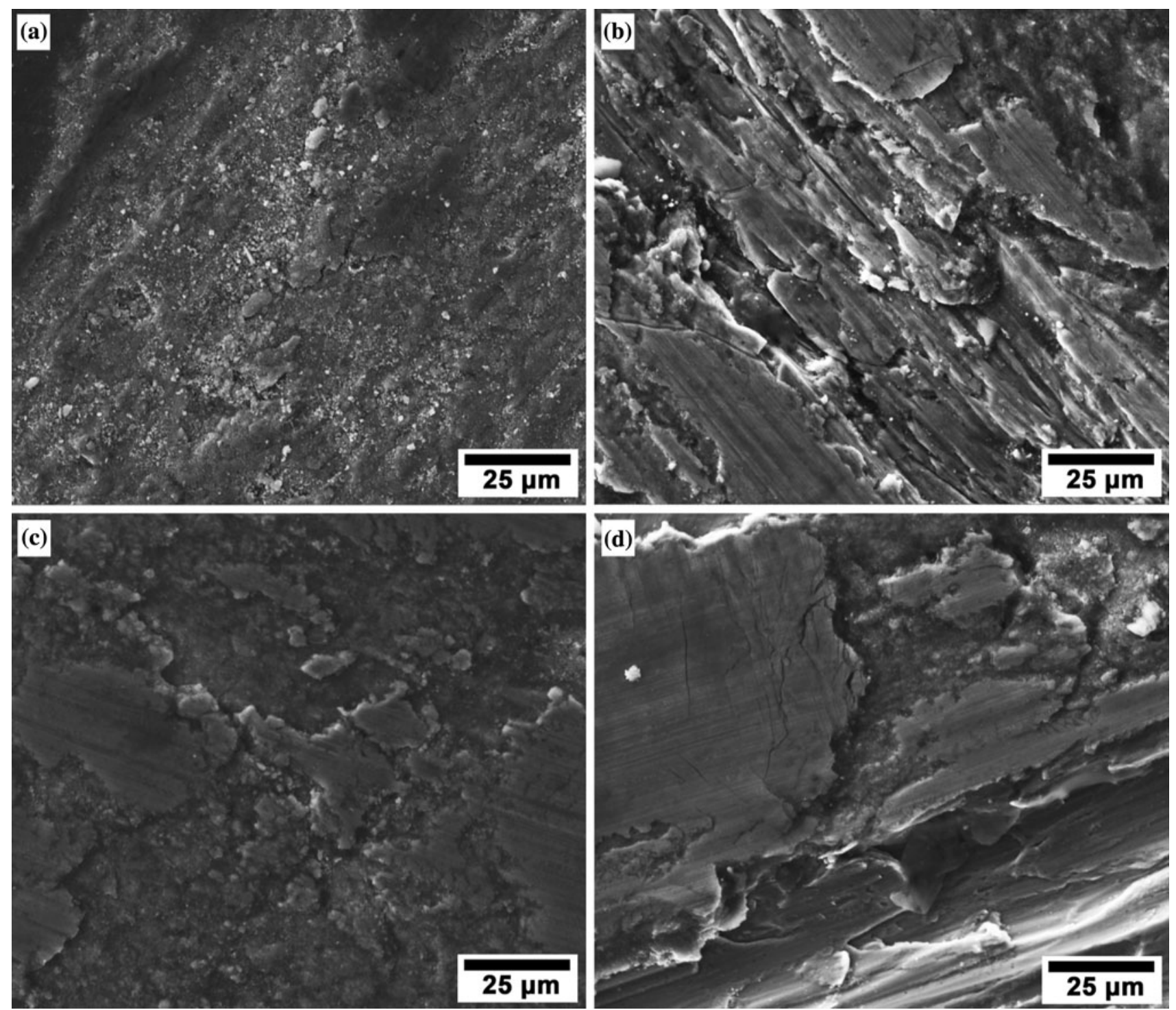

Fig. 5 Typical SEM images (high magnification) of friction path of $\mathrm{Cu}$ samples after HPT (a), after HPT with subsequent annealing at $100{ }^{\circ} \mathrm{C}$ during $1 \mathrm{~h} \mathrm{(b)}$, after HPT with subsequent annealing at $200{ }^{\circ} \mathrm{C}$ during $1 \mathrm{~h}(\mathbf{c})$, and after HPT with subsequent annealing at $300{ }^{\circ} \mathrm{C}$ during $1 \mathrm{~h}(\mathbf{d})$

results because there was a total increase of $\sim 3.5 \%$ in the microhardness [(150-145)/145 × $100 \%]$.

Correlations of electroconductivity, wear properties, and microstructural parameters of HPT copper samples upon annealing

The electroconductivity and wear resistance seem to be mostly sensitive to microstructural parameters, and they are not significantly dependent on the texture evolution. As the mean grain size increases and the dislocation density decreases upon annealing, the electroconductivity increases, and the wear rate correspondingly decreases (Tables 1, 2; Fig. 6). But if a plot of microhardness is included in the same graph, it is evident that the strength of copper drops significantly after annealing at temperatures higher than $150{ }^{\circ} \mathrm{C}$. As the strength is of importance for copper applications, it is apparent that the optimal conditions for the heat treatment of HPT copper lies inside the circle shown in Fig. 6. Within this area, the highest strength of copper is combined with a moderate wear rate and sufficient electroconductivity. In addition, annealing at a temperature of $150^{\circ} \mathrm{C}$ will provide no degradation in mechanical and functional properties under exploitation conditions including short-term heating up to $110^{\circ} \mathrm{C}$. It is apparent that the SPD followed by annealing at $150{ }^{\circ} \mathrm{C}$ produces the optimal combination of such key properties for copper as strength, electroconductivity, wear resistance, 


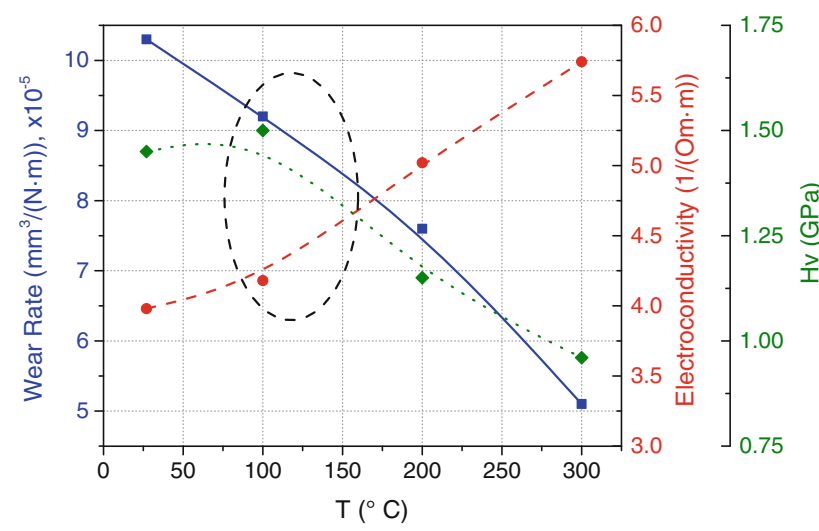

Fig. 6 Wear rate, electroconductivity, and microhardness in HPT copper annealed for $1 \mathrm{~h}$ at different temperatures

and thermal stability where typically these properties have opposing characteristics.

\section{Conclusions}

1. Annealing of $\mathrm{Cu}$ specimens processed by HPT leads to an increase in the electroconductivity and a decrease in the wear rate.

2. A minor increase in microhardness in HPT copper specimen annealed at the relatively low temperature of $100{ }^{\circ} \mathrm{C}$ is most likely due to a change in texture upon annealing. This annealing leads to an increase in the Taylor factor by $\sim 5 \%$ which is in good agreement with the increase in the microhardness level also by $\sim 5 \%$.

3. It is apparent that low temperature annealing of HPT copper may assist in producing optimal properties in the specimens including high strength and electroconductivity with a lower wear rate.

Acknowledgements This study was supported by the Ministry of Education and Science, Russia, under Grant No. 14.A18.21.1986, and in part by the European Research Council under ERC Grant Agreement No. 267464-SPDMETALS. The authors are grateful to the personnel of the Joint Research Centre, Belgorod State University, for their assistance with instrumental analysis.

\section{References:}

1. Valiev RZ, Islamgaliev RK, Alexandrov IV (2000) Bulk nanostructured materials from severe plastic deformation. Prog Mater Sci 45:103-189

2. Valiev RZ, Sabirov I, Zhilyaev AP, Langdon TG (2012) Bulk nanostructured metals for innovative applications. JOM 64: $1134-1142$

3. Faghihi S, Zhilyaev AP, Szpunar JA, Azari F, Vali H, Tabrizian M (2007) Nanostructuring of a titanium material by high-pressure torsion improves pre-osteoblast attachment. Adv Mater 19: 1069-1073

4. Shangina DV, Bochvar NR, Dobatkin SV (2010) Structure and properties of $\mathrm{Cu}-\mathrm{Cr}$ alloys subjected to shear under pressure and subsequent heating. Russ Metall (Metally) 11:1046-1052

5. Shangina DV, Maksimenkova YuM, Bochvar NR, Dobatkin SV (2011) Behavior of an ultrafine-grained $\mathrm{Cu}-\mathrm{Zr}$ alloy in heating, Russian Metallurgy (Metally). Russ Metall (Metally) 11:1069-1073

6. Dopita M, Janeček M, Kužel R, Seifert HJn, Dobatkin S (2010) Microstructure evolution of CuZr polycrystals processed by highpressure torsion. J Mater Sci 45:4631-4644. doi:10.1007/s10853010-4643-9

7. Rigney DA (1988) Sliding wear of metals. Ann Rev Mater Sci 18:141-163

8. Emge A, Karthikeyan S, Kim HJ, Rigney DA (2007) The effect of sliding velocity on the tribological behavior of copper. Wear 263:614-618

9. Emge A, Karthikeyan S, Rigney DA (2009) The effects of sliding velocity and sliding time on nanocrystalline tribolayer development and properties in copper. Wear 267:562-567

10. Rigney D, Karthikeyan S (2010) The evolution of tribomaterial during sliding: a brief introduction. Tribol Lett 39:3-7

11. Zhilyaev AP, Shakhova I, Belyakov A, Kaibyshev R, Langdon TG (2013) Wear resistance and electroconductivity in copper processed by severe plastic deformation. Wear 305:89-99

12. Komura S, Horita Z, Nemoto M, Langdon TG (1999) Influence of stacking fault energy on microstructural development in equalchannel angular pressing. J Mater Res 14:4044-4050

13. Dobatkin SV, Szpunar JA, Zhilyaev AP, Cho J-Y, Kuznetsov AA (2007) Effect of the route and strain of equal-channel angular pressing on structure and properties of oxygen-free copper. Mater Sci Eng A 462:132-138

14. Huang WH, Chang L, Kao PW, Chang CP (2001) Effect of die angle on the deformation texture of copper processed by equal channel angular extrusion. Mater Sci Eng A 307:113-118

15. Miyamoto H, Erb U, Koyama T, Mimaki T, Vinogradov A, Hashimoto S (2004) Microstructure and texture development of copper single crystals deformed by equal-channel angular pressing. Philos Mag Lett 84:235-243

16. Dalla Torre F, Lapovok R, Sandlin J, Thomson PF, Davies CHJ, Pereloma EV (2004) Microstructures and properties of copper processed by equal channel angular extrusion for 1-16 passes. Acta Mater 52:4819-4832

17. Furukawa M, Fukuda Y, Oh-ishi K, Horita Z, Langdon TG (2006) An investigation of deformation in copper single crystals using equal-channel angular pressing. Mater Sci Forum 503-504:113-118

18. Lugo N, Llorca N, Cabrera JM, Horita Z (2008) Microstructures and mechanical properties of pure copper deformed severely by equal-channel angular pressing and high pressure torsion. Mater Sci Eng A 477:366-371

19. Jiang H, Zhu YT, Butt DP, Alexandrov IV, Lowe TC (2000) Microstructural evolution, microhardness and thermal stability of HPT-processed Cu. Mater Sci Eng A 290:128-138

20. Wetscher F, Vorhauer A, Pippan R (2005) Strain hardening during high pressure torsion deformation. Mater Sci Eng A 410-411:213-216

21. Horita Z, Langdon TG (2005) Microstructures and microhardness of an aluminium alloy and pure copper after processing by highpressure torsion. Mater Sci Eng A 410-411:422-425

22. Swaminathan S, Shankar MR, Rao BC, Compton WD, Chandrasekar S, King AH, Trumble KP (2007) Severe plastic deformation (SPD) and nanostructured materials by machining. J Mater Sci 42:1529-1541. doi:10.1007/s10853-006-0745-9

23. Wang K, Tao NR, Liu G, Lu J, Lu K (2006) Plastic straininduced grain refinement at the nanometer scale in copper. Acta Mater 54:5281-5291 
24. Sadykov FA, Barykin NP, Aslanyan IR (1997) The influence of strain-heat processing on copper wear. Wear 212:160-164

25. Iglesias P, Bermúdez MD, Moscoso W, Chandrasekar S (2010) Influence of processing parameters on wear resistance of nanostructured OFHC copper manufactured by large strain extrusion machining. Wear 268:178184

26. Zhang YS, Wang K, Han Z, Liu G (2007) Dry sliding wear behaviour of copper with nano-scaled twins. Wear 262: $1463-1470$

27. Yao B, Han Z, Lu K (2012) Correlation between wear resistance and subsurface recrystallization structure in copper. Wear 294-295:438-445

28. Islamgaliev RK, Pekala K, Pekala M, Valiev RZ (1997) The determination of the grain boundary width of ultrafine grained copper and nickel from electrical resistivity measurements. Phys Stat Sol A 162:559-566

29. Zhilyaev AP, Gimazov AA, Raab GI, Langdon TG (2008) Using high-pressure torsion for the cold-consolidation of copper chips produced by machining. Mater Sci Eng A 486:123-126

30. Figueiredo RB, Cetlin PR, Langdon TG (2011) Using finite element modeling to examine the flow processes in quasi-constrained high-pressure torsion. Mater Sci Eng A 528:8198-8204
31. Figueiredo RB, Pereira PHR, Aguilar MTP, Cetlin PR, Langdon TG (2012) Using finite element modeling to examine the temperature distribution in quasi-constrained high-pressure torsion. Acta Mater 60:3190-3198

32. van den Beukel A (1979) Dislocation production in cold worked copper. Scripta Metal 13:83-86

33. Rigney DA (1979) Dislocation content at large plastic strains. Scripta Metal 13:353-354

34. Huang X, Hansen N, Tsuji N (2006) Hardening by annealing and softening by deformation in nanostructured metals. Science 312:249-251

35. Tang F, Schoeunung JM (2008) Strain hardening in nanocrystalline or ultrafine-grained metals: a mechanistic explanation. Mater Sci Eng A 493:101-103

36. Su LH, Lu C, Tieu AK, He LZ, Zhang Y, Wexler D (2011) Vacancy-assisted hardening nanostructured metals. Mater Let 65:514-516

37. Kamikawa N, Huang X, Tsuji N, Hansen N (2009) Strengthening mechanisms in nanostructured high-purity aluminium deformed to high strain and annealed. Acta Mater 57:4198-4208 